\title{
Pulmonary functions of patients with isolated mandibular fractures: a preliminary report
}

\author{
Bamidele Adetokunbo Famurewa ${ }^{1}$, Fadekemi Olufunmilayo Oginni ${ }^{1}$, \\ Stephen Babatunde Aregbesola', Gregory Efosa Erhabor ${ }^{2}$ \\ ${ }^{1}$ Department of Oral/Maxillofacial Surgery and Oral Pathology, ${ }^{2}$ Department of Medicine (Pulmonology Unit), \\ Obafemi Awolowo University, Ile-Ife, Nigeria
}

\begin{abstract}
J Korean Assoc Oral Maxillofac Surg 2020;46:36-40)
Objectives: The aim of this study was to evaluate pulmonary function in patients with mandibular fractures and to determine the pattern of pulmonary functions in these patients.

Materials and Methods: This was a cross-sectional study of pulmonary functions in Nigerian non-smoking patients with isolated mandibular fractures managed at our health institution from December 2015 to June 2017. Forced vital capacity (FVC), forced expiratory volume in one second (FEV $)_{1}$, peak expiratory flow rate (PEFR), and ratio of $\mathrm{FEV}_{1}$ to $\mathrm{FVC}\left(\mathrm{FEV}_{1} / \mathrm{FVC}\right)$ were measured for all participants using a portable spirometer just before treatment. The pulmonary indices were compared with the predicted reference values for Nigerians to determine the respiratory pattern.

Results: Forty participants consisting of six females $(15.0 \%)$ and thirty-four males $(85.0 \%)$ with a female to male ratio of 1:5.7 were included in this study. The mean patient age was $34.5 \pm 13.1$ years (range, 17-63 years). The mean FVC, FEV, FEV $_{1} / F V C$, and PEFR were 3.8 $\pm 1.2 \mathrm{~L}, 3.0 \pm 1.0 \mathrm{~L}$, $74.3 \% \pm 13.8 \%$, and $5.2 \pm 2.2 \mathrm{~L} / \mathrm{s}$, respectively. Comparison of data with predicted values revealed that 17 subjects (42.5\%) had normal pulmonary function pattern while 23 subjects (57.5\%) had features suggestive of obstructive and restrictive pulmonary function patterns.

Conclusion: Isolated mandibular fractures presented with abnormal pulmonary function pattern.
\end{abstract}

Key words: Pulmonary function, Mandibular fractures, Spirometry, Airway obstruction

[paper submitted 2019. 8. 10 / revised 1st 2019. 10. 17, 2nd 2019. 11. 14, 3rd 2019. 11. 20 / accepted 2019. 11. 24]

\section{Introduction}

Mandibular fractures do not typically present with respiratory difficulty or pulmonary complications ${ }^{1,2}$. However, there are rare cases of mandibular fractures with related airway obstruction mostly due to loss of anterior tongue support and mandibular attachment of genioglossus ${ }^{2-4}$. In addition, treatment of mandibular fractures by closed reduction with maxillomandibular fixation has been reported to cause airway obstruction with potentially fatal implications in patients with

\section{Bamidele Adetokunbo Famurewa}

Department of Oral/Maxillofacial Surgery and Oral Pathology, Obafemi Awolowo University, Ile-Ife 220282, Nigeria

TEL: +234-8061284397

E-mail:murewadele83@gmail.com

ORCID: https://orcid.org/0000-0001-5426-4130

(c) This is an open-access article distributed under the terms of the Creative Commons Attribution Non-Commercial License (http://creativecommons.org/ licenses/by-nc/4.0/), which permits unrestricted non-commercial use, distribution, and reproduction in any medium, provided the original work is properly cited.

Copyright (C) 2020 The Korean Association of Oral and Maxillofacial Surgeons. All rights reserved. respiratory disease $\mathrm{e}^{5-7}$.

The pulmonary function of patients with mandibular fractures without rare, emergent airway compromise is still unknown and whether these stable isolated mandibular fractures present with normal or deranged pulmonary function has not been evaluated. The aim of this study was therefore to evaluate the pulmonary function and patterns in patients with isolated mandibular fractures.

\section{Materials and Methods}

This was a cross-sectional study of 40 Nigerian patients with clinical and radiological features of isolated mandibular fractures who were managed at the Obafemi Awolowo University Teaching Hospitals Complex (OAUTHC), Ile-Ife, from December 2015 to June 2017. The study was approved by the Ethics and Research Committee of the OAUTHC (ECR/2015/05/08). All recruited patients signed informed consent forms. The study was conducted in compliance with 
the Declaration of Helsinki. None of the studied participants presented with clinical features of respiratory distress or impending airway compromise.

Exclusion criteria included subjects with pre-existing lung pathology or respiratory disease, current smokers or those who stopped smoking less than two years ago, and subjects whose occupations might predispose them to impaired pulmonary function, such as cement factory, bakery, sawmill, and wheat flour mill workers.

Biodata were recorded and weight and height of subjects were measured using a weighing scale (Seca Scales; Seca, Birmingham, UK) and stadiometer (CMS Weighing Equipment, London, UK). Forced vital capacity (FVC), forced expiratory volume in one second $\left(\mathrm{FEV}_{1}\right)$, peak expiratory flow rate (PEFR), and ratio of $\mathrm{FEV}_{1}$ to $\mathrm{FVC}\left(\mathrm{FEV}_{1} / \mathrm{FVC}\right)$ were measured for all participants just before treatment using a Spirobank G spirometer (Medical International Research, Rome, Italy). This spirometer has a turbine sensor that obviates calibration.(Fig. 1) The procedure was explained to the participants and was performed according to the American Thoracic Society and European Thoracic Society standards and recommendations ${ }^{8}$.(Fig. 2)

Predicted values of pulmonary function parameters (FVC [L], $\mathrm{FEV}_{1}[\mathrm{~L}], \mathrm{FEV}_{1} / \mathrm{FVC}[\%]$, and PEFR [L/s]) were determined using reference values for Nigerians ${ }^{8}$. The measured pulmonary function values from all patients were compared with the predicted values. Participants with $\mathrm{FEV}_{1} / \mathrm{FVC}$ less than $70 \%$ were categorized as having obstructive pulmonary function abnormality. Participants with FVC values less than $80 \%$ of the predicted value were classified as having a restrictive pulmonary function pattern, while those with FVC values greater than or equal to $80 \%$ of the predicted value

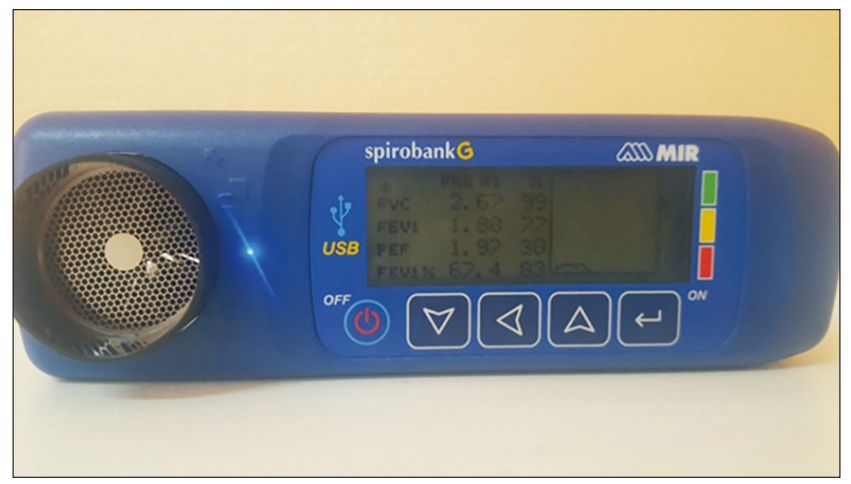

Fig. 1. Portable office spirometer used for pulmonary function tests.

Bamidele Adetokunbo Famurewa et al: Pulmonary functions of patients with isolated mandibular fractures: a preliminary report. J Korean Assoc Oral Maxillofac Surg 2020 were categorized as having a normal pulmonary function pat$\operatorname{tern}^{9,10}$.

Data analysis was performed using IBM SPSS Statistics (ver. 21; IBM Corp., Armonk, NY, USA). Descriptive statistics were carried out for socio-demographic variables. Descriptive variables that were continuous parameters such as mean, median, minimum, maximum, and measures of variability were determined. For descriptive variables that were categorical, simple frequencies and percentages were determined. Fisher's exact test was used to determine any association between pulmonary function pattern and mandibular fracture sites. A $P$-value less than 0.05 was considered significant.

\section{Results}

Forty subjects with isolated mandibular fractures consisting of six females $(15.0 \%)$ and 34 males $(85.0 \%)$ with a female to male ratio of 1:5.7 were included in this study. The mean age of participants was $34.5 \pm 13.1$ years, with a range of 17 to 63 years. Most participants $(45 \%)$ were in the third decade of life.

Road traffic crashes (automobile, motorcycle, and pedestrian injuries) accounted for $87.5 \%$ of all sampled fractures while assaults (5\%), sports-related accidents (5\%), and occupational accidents $(2.5 \%)$ were responsible for the remaining fractured mandibles.

Twenty-three patients $(57.5 \%)$ presented with unilateral mandibular fracture, 16 patients $(40.0 \%)$ had bilateral mandibular fracture, and double unilateral mandibular fracture was seen in one subject $(2.5 \%)$. The body of the mandible

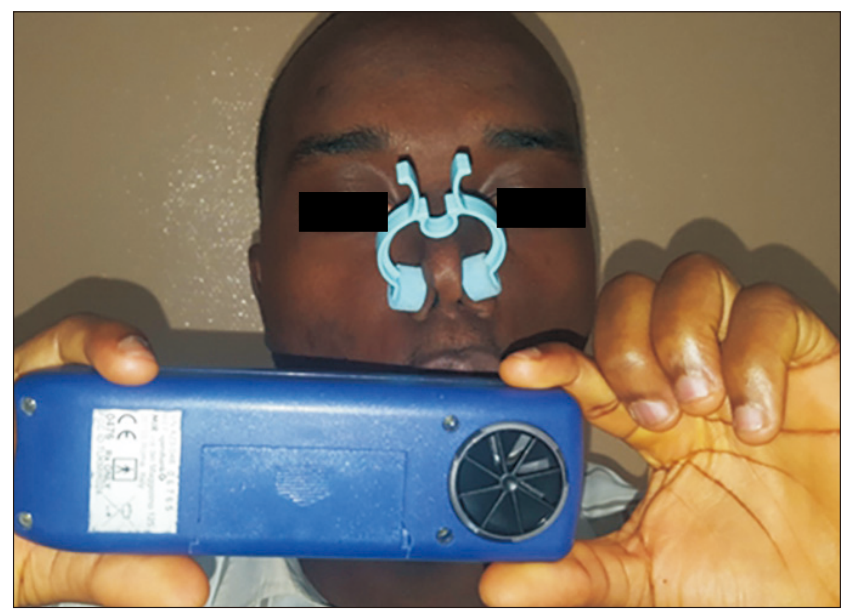

Fig. 2. A study participant undergoing spirometry testing. Bamidele Adetokunbo Famurewa et al: Pulmonary functions of patients with isolated mandibular fractures: a preliminary report. J Korean Assoc Oral Maxillofac Surg 2020 
Table 1. Pulmonary function pattern of participants

\begin{tabular}{cr}
\hline Pulmonary function pattern & $\mathrm{n}(\%)$ \\
\hline Normal & $17(42.5)$ \\
Obstructive & $15(37.5)$ \\
Restrictive & $8(20.0)$ \\
Total & $40(100)$ \\
\hline
\end{tabular}

Bamidele Adetokunbo Famurewa et al: Pulmonary functions of patients with isolated mandibular fractures: a preliminary report. J Korean Assoc Oral Maxillofac Surg 2020

Table 2. Distribution of participants' fracture sites and pulmonary function patterns

\begin{tabular}{lccc}
\hline \multirow{2}{*}{ Fracture site } & \multicolumn{3}{c}{ Pulmonary function pattern } \\
\cline { 2 - 4 } & Normal & Obstructive & Restrictive \\
\hline Symphysis & $1(20)$ & $2(40)$ & $2(40)$ \\
Parasymphysis & $6(50)$ & $4(33.3)$ & $2(16.7)$ \\
Body & $15(48.4)$ & $9(29)$ & $7(22.6)$ \\
Angle & $2(28.6)$ & $4(57.1)$ & $1(14.3)$ \\
Ramus & $1(50)$ & $0(0)$ & $1(50)$ \\
\hline
\end{tabular}

Fisher's exact test used; $P$-value $=1.000$

Values are presented as number (\%).

Bamidele Adetokunbo Famurewa et al: Pulmonary functions of patients with isolated mandibular fractures: a preliminary report. J Korean Assoc Oral Maxillofac Surg 2020

was the most fractured site (54.4\%) with fractures occurring at mandibular parasymphyseal and angle regions, accounting for $21.1 \%$ and $12.3 \%$ of fractured sites, respectively.

The mean FVC, $\mathrm{FEV}_{1}, \mathrm{FEV}_{1} / \mathrm{FVC}$, and PEFR were $3.8 \pm 1.2$ L, $3.0 \pm 1.0 \mathrm{~L}, 74.3 \% \pm 13.8 \%$, and $5.2 \pm 2.2 \mathrm{~L} / \mathrm{s}$, respectively. As stated under Materials and Methods section, 17 subjects (42.5\%) had normal pulmonary function pattern while 23 subjects $(57.5 \%)$ had abnormal pulmonary function patterns (obstructive and restrictive).(Table 1) There was no statistically significant association between pulmonary function pattern and mandibular fracture sites.(Table 2) Table 3 shows the participants' pulmonary function patterns at the 7th postoperative week.

\section{Discussion}

Age and sex distributions of the participants in this study were similar to previous reports on maxillofacial fractures in Nigeria, in which mandibular fractures are prevalent among men and most common in the third decade of life in both $\operatorname{sexes}^{11}$. Road traffic crash was responsible for most of the mandibular fractures in this study. This is in agreement with the findings of Chrcanovic et al. ${ }^{12}$ and Oginni et al. ${ }^{13}$ but in contrast to etiological factors in developed nations, in which assaults and interpersonal violence are the leading causes of mandibular fractures ${ }^{14}$.

The mean preoperative values of measured pulmonary function parameters in the present study were similar to those
Table 3. Comparison of participants' pulmonary function patterns at baseline (preoperatively) and 7th postoperative week

\begin{tabular}{lcccc}
\hline & \multicolumn{3}{c}{ Pulmonary function pattern } & \\
\cline { 2 - 3 } & Normal & Obstructive & Restrictive & \\
\hline Baseline & $17(42.5)$ & $15(37.5)$ & $8(20.0)$ & 40 \\
7th postoperative week & $36(94.7)$ & $2(5.3)$ & $0(0)$ & $38^{1}$ \\
\hline
\end{tabular}

${ }^{1}$ Two participants failed to come for review and pulmonary function test at the 7 th postoperative week.

Values are presented as number (\%).

Bamidele Adetokunbo Famurewa et al: Pulmonary functions of patients with isolated mandibular fractures: a preliminary report. J Korean Assoc Oral Maxillofac Surg 2020

in the report by Akhiwu et al. ${ }^{6}$. In the previous report, however, the authors failed to measure $\mathrm{FEV}_{1} / \mathrm{FVC}$ and interpret pulmonary function parameters of each subject in the study. Therefore, categorization of patients (whose parameters were measured) into different respiratory function patterns (normal, obstructive, and restrictive) was not performed. Despite the fact that mean pulmonary function parameters of all participants were normal compared with predicted values ${ }^{9,15}$, analysis of measured pulmonary function parameters for each participant revealed that more than half of the participants had abnormal respiratory function (obstructive and restrictive respiratory patterns), while 17 participants (42.5\%) had normal respiratory function pattern.

The implication of this finding is that impaired pulmonary function can be found in patients with mandibular fractures with no lung disease, previous history of smoking, or occupational exposure that could predispose them to abnormal respiratory function. Our finding is unexpected in this group of stable patients with no airway compromise and background pulmonary disease. This is in sharp contrast to the severe and life-threatening cases of airway compromise following mandibular fractures often managed in emergency rooms ${ }^{2-4}$.

In cases of isolated mandibular fractures in conscious patients with no comminuted or severely impacted anterior fractured segment, as in the present study participants, there is some degree of pulmonary dysfunction that patients have ability to cope with. This is in line with the observation by Chen et al. ${ }^{16}$ who evaluated the relationship between upper airway space and changes in hyoid position following mandibular fractures in 180 patients and 30 volunteers and found that mandibular fractures are closely related to upper airway and hyoid position. The authors concluded that bilateral mandibular body and parasymphyseal fractures have a significant influence on oropharyngeal and laryngopharyngeal portions of the upper airway with consequent respiratory function impairments ${ }^{15}$. This may lead to an unstable tongue base with backward and downward displacement of the fractured ante- 
rior segment in comminuted and unfavorable parasymphyseal fractures $^{2,4,16}$.

Of all unilateral mandibular fractures, only unilateral mandibular body fracture was found to significantly affect the laryngopharyngeal airway ${ }^{16}$. There was no association between the pulmonary function pattern and fracture site in the present study, which was probably due to the small sample size and exclusion of mandibular condylar fractures. Furthermore, sublingual hematoma and edema, which are clinical signs of mandibular fractures, were also found to reduce tongue space and tend to displace the tongue backward, resulting in narrowing of the oropharynx ${ }^{16}$, and pain from a fractured mandible may be responsible for suboptimal pulmonary function found in these participants with isolated fractured mandibles.

The limitations of this study include its small sample size, heterogeneous duration of injury, and non-assessment of presenting pain before pulmonary function tests were done. In addition, oxygen saturation in the study participants was not evaluated. Further study with a large sample size to determine pulmonary function in stable mandibular fracture patients with similar duration of injury and baseline assessment of pain and oxygen saturation is warranted.

\section{Conclusion}

These drawbacks notwithstanding, isolated mandibular fractures may be associated with impaired pulmonary function parameters, as some participants presented with values suggestive of obstructive and restrictive pulmonary function patterns.

\section{ORCID}

Bamidele Adetokunbo Famurewa, https://orcid.org/00000001-5426-4130

Fadekemi Olufunmilayo Oginni, https://orcid.org/00000002-7297-1055

Stephen Babatunde Aregbesola, https://orcid.org/00000001-5225-019X

Gregory Efosa Erhabor, https://orcid.org/0000-0002-84789189

\section{Authors' Contributions}

B.A.F. participated in study design, data collection, and drafted the manuscript. F.O.O., S.B.A., and G.E.E. helped with study design, supervised the study and reviewed the manuscript. All authors read and approved the final draft.

\section{Ethics Approval and Consent to Participate}

The study was approved by the Ethics and Research Committee of the OAUTHC (ECR/2015/05/08). All recruited patients signed informed consent forms.

\section{Conflict of Interest}

No potential conflict of interest relevant to this article was reported.

\section{References}

1. Chacon GE, Larsen PE. Principles of management of mandibular fractures. In: Miloro M, Ghali GE, Larsen P, Waite P, Peterson LJ, Alexander CM, eds. Peterson's principles of oral and maxillofacial surgery. 2nd ed. Ontario: BC Decker; 2004.

2. Papadiochos I, Goutzanis L, Petsinis V. Flail mandible and immediate airway management: traumatic detachment of mandibular lingual cortex results in obstructive dyspnea and severe odynophagia. J Craniofac Surg 2017;28:1311-4.

3. Bavitz JB, Collicott PE. Bilateral mandibular subcondylar fractures contributing to airway obstruction. Int J Oral Maxillofac Surg 1995;24:273-5.

4. Fujioka M, Hayashida K, Saijo H. Split fracture and displacement of mandibular lingual cortical plate of mandibular symphysis requires fixation. Trauma Cases Rev 2015;1. doi: 10.23937/24695777/1510019.

5. Williams JG, Cawood JI. Effect of intermaxillary fixation on pulmonary function. Int J Oral Maxillofac Surg 1990;19:76-8.

6. Akhiwu BI, Akhiwu HO, Saheeb BD, Habeeb MM. The effect of anesthesia on the ventilatory functions of patients with Maxillomandibular fixation. J West Afr Coll Surg 2016;6:95-112.

7. Kim $\mathrm{CH}$, Kim MS. A clinical study on pulmonary function after intermaxillary fixation. J Korean Assoc Oral Maxillofac Surg 1999;25:361-6.

8. Miller MR, Hankinson J, Brusasco V, Burgos F, Casaburi R, Coates A, et al. Standardisation of spirometry. Eur Respir J 2005;26:31938.

9. Patrick JM, Femi-Pearse D. Reference values for FEV1 and FVC in Nigerian men and women: a graphical summary. Niger Med J 1976;6:380-5.

10. Erhabor GE, Fatusi S, Obembe OB. Pulmonary functions in ARCwelders in Ile-Ife, Nigeria. East Afr Med J 2001;78:461-4.

11. Ibikunle A, Taiwo A, Braimah R, Gbotolorun O. Changing pattern in the treatment of mandibular fractures in North-Western Nigeria. Afr J Trauma 2016;5:36-42.

12. Chrcanovic BR, Abreu MH, Freire-Maia B, Souza LN. 1,454 mandibular fractures: a 3-year study in a hospital in Belo Horizonte, Brazil. J Craniomaxillofac Surg 2012;40:116-23.

13. Oginni FO, Oladejo T, Alake DP, Oguntoba JO, Adebayo OF. Facial bone fractures in Ile-Ife, Nigeria: an update on pattern of presentation and care. J Maxillofac Oral Surg 2016;15:184-90.

14. Afrooz PN, Bykowski MR, James IB, Daniali LN, Clavijo-Alvarez JA. The epidemiology of mandibular fractures in the United States, part 1: a review of 13,142 cases from the US National Trauma Data Bank. J Oral Maxillofac Surg 2015;73:2361-6.

15. Fawibe AE, Odeigah LO, Saka MJ. Reference equations for spirometric indices from a sample of the general adult population in 
Nigeria. BMC Pulm Med 2017;17:48.

16. Chen LJ, Zhao MC, Pan XF, Wei YQ, Wang DY. X-cephalometric study of different parts of the upper airway space and changes in hyoid position following mandibular fractures. West Indian Med J 2013;62:642-8.
How to cite this article: Famurewa BA, Oginni FO, Aregbesola SB, Erhabor GE. Pulmonary functions of patients with isolated mandibular fractures: a preliminary report. J Korean Assoc Oral Maxillofac Surg 2020;46:36-40. https://doi.org/10.5125/jkaoms.2020.46.1.36 